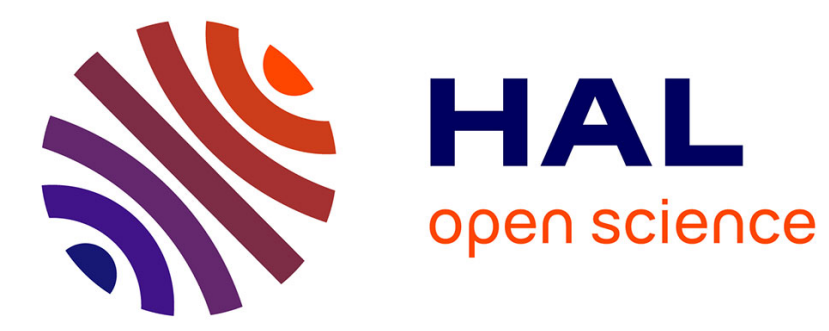

\title{
In-Service Falcon Lightning Strike Events
}

M. Roussel, F. Tristan, F. Fustin, A. Even, Arnaud Chazottes, P. Lalande

\section{To cite this version:}

M. Roussel, F. Tristan, F. Fustin, A. Even, Arnaud Chazottes, et al.. In-Service Falcon Lightning

Strike Events. ICOLSE 2015, Sep 2015, TOULOUSE, France. 10.1049/ic.2015.0202 . hal-01521919

\section{HAL Id: hal-01521919 \\ https://hal.science/hal-01521919}

Submitted on 12 May 2017

HAL is a multi-disciplinary open access archive for the deposit and dissemination of scientific research documents, whether they are published or not. The documents may come from teaching and research institutions in France or abroad, or from public or private research centers.
L'archive ouverte pluridisciplinaire HAL, est destinée au dépôt et à la diffusion de documents scientifiques de niveau recherche, publiés ou non, émanant des établissements d'enseignement et de recherche français ou étrangers, des laboratoires publics ou privés. 


\title{
IN-SERVICE FALCON LIGHTNING STRIKE EVENTS
}

\author{
M. Roussel*, F. Tristant*, F. Fustin*, A. Even*, A. Chazottes ${ }^{\dagger}$, P. Lalande ${ }^{\dagger}$ \\ * Dassault Aviation - 78 Quai Marcel Dassault-Cedex 300 - 92552 Saint-Cloud Cedex (France) \\ Maxime.roussel@dassault-aviation.com; Fabrice.Tristant@dassault-aviation.com \\ Fabian.Fustin@dassault-aviation.com; Fabien.Terrade@dassault-aviation.com \\ Andre.Even@dassault-aviation.com \\ 'ONERA - 29 Av. De la division Leclerc 92320 Chatillon (France) \\ Arnaud.chazottes@onera.fr; Philippe.lalande@onera.fr
}

Keywords: Lightning strike events, Falcon fleet, influential factors, damages distribution, attachment, sweeping, computations

\section{Abstract}

This paper focuses on the lightning events encountered by Falcons fleet (F900, F2000 and F7X) during a 10 years period, between the 1st January 2003 and 12th July 2013. During this period, 164 lightning strikes have been collected in a database which provides an interesting feedback.

A considerable amount of researches have been accomplished during last decades to highlight the mechanisms whereby aircrafts are struck by lightning. Strike occurrence data, principally for commercial aircrafts, have been collected for many years. However, much less data is available for smaller aircrafts like private jets. Are these statistics gathered consistent with Dassault Aviation in-flight lightning events experience?

In a first part, this study will be focused on the analysis of Falcon lightning events as a function of the following parameters:

- Flight hours and cycles

- Type of Falcon

- Altitude

- $\quad$ Flight path (climbing, cruise or descent)

The different factors which may influence the lightning strike rate will be highlighted and compared to data gathered until now. Moreover, dedicated analysis will be performed on the zone 3, where an attachment of the lightning channel is unlikely.

In a second part, a lightning attachment points mapping will be established. The aim is to highlight lightning strike areas with higher probability of encountering attachment or sweeping phenomenon and correlate these observations with standard aircrafts zoning and computations performed by ONERA.

\section{Introduction}

Lightning strikes can affect flight operations and result in costly delays and service interruptions and repairs. Despite strike to aircrafts are relatively common, they rarely result in significant impact to the safe operability of the aircrafts.

Falcons are efficiently protected against lightning strike adverse effects, their protection is function of areas exposure levels defined by the zoning which is established in accordance with normative ARP-5414/ED-91 documents.

In service experience is a very interesting feedback for aircraft manufacturers to increase the lightning phenomenology understanding.

\section{Falcon fleet lightning events - reports frequency}

An interesting parameter to quantify lightning threat is its frequency of occurrence. Its order of magnitude which emerges from all the data gathered since decades on commercial aircraft corresponds to a lightning strike comprising between 1500 and 3000 flight hours, roughly estimated as one time per year.

All the lightning strike events encountered during a decade on F900, F2000 and F7X were compiled from forms filled out by operators which describe the relevant parameters: date of event, localization/country, flight phase, altitude, attachment points, damaged areas...

The following graph details the lightning events registered on Falcon fleet throughout this decade. It compares Falcon family cumulated number of lightning strikes registered in the period of study (blue curve) to the yearly fleet flight hours. 


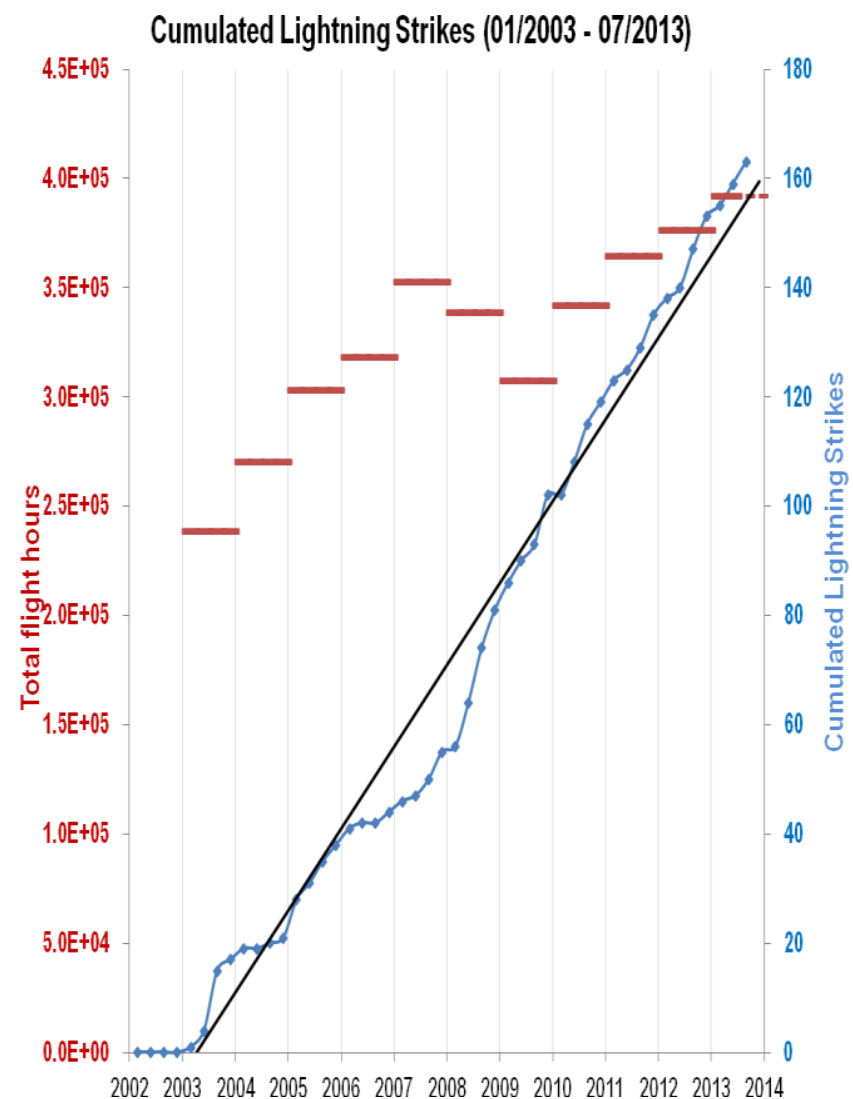

Figure 1. Falcon fleet cumulated lightning strikes (Total flight hours: around 3.6 millions)

The yearly fleet flight hours increased from 2003 to 2008 . The significant decreases during 2008 and 2009 was a direct consequence of the market fluctuations.

The Falcon fleet cumulated about 3,600,000 flight hours during this decade and registered 164 lightning strikes. It means that a lightning strike is reported to Dassault Aviation every 22,000 flight hours or around every 11,000 flight cycles (average time per flight is approximately $2 \mathrm{~h}$ ).

These statistics suggest a lower lightning strike frequency of occurrence compared to commercial aircrafts, however the difference partially finds its root cause in the fact that lightning strike are not systematically reported by operators. It is per consequence difficult to precisely evaluate Falcon fleet frequency of occurrence.

There are nonetheless some particularities which may reduce their lightning exposure time:

- Falcon jets flexibility which enables them more easily to avoid bad atmospheric conditions. In comparison, commercial aircrafts have to respect strict flight schedules and congested air traffic lanes which increased their lightning strike exposure time.
- Falcons jets flight profiles differ from commercial ones. Take-off and landing phases are stepper. As a consequence, Falcons jets spend less time than commercial aircrafts at lower and intermediate altitudes where the lightning activity is the most important. Cruise altitude is also higher than for commercial aircrafts. Even if it is relatively rare to encounter lightning strike at cruise altitude, this parameter is heading in the right direction to explain this low rate of lightning strike reported:

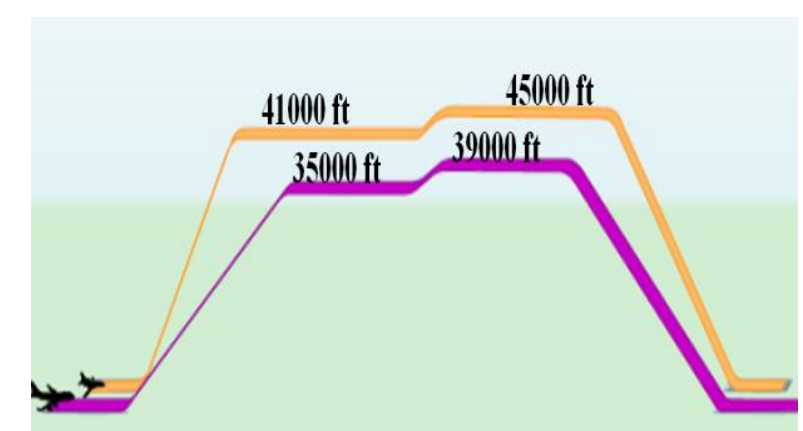

Figure 2. Falcon jets and commercial aircrafts typical flight profiles comparison

- Falcon jets sizes are significantly lower than commercial aircrafts ones. Their presence in or next to a cumulonimbus, characterized by its high electrical field environment, may have a lower influence on electrical field disturbance. The leader initiation process at commercial aircrafts extremities may appear at a lower electrical field intensity resulting in an increased likelihood of strike initiation.

To go in further details, the frequency of lightning strike reported is presented thereafter in function of Falcon type. The number of flight hours accumulated by each Falcon type is represented with blue bars and the frequency of lightning strike reported in red bars. 


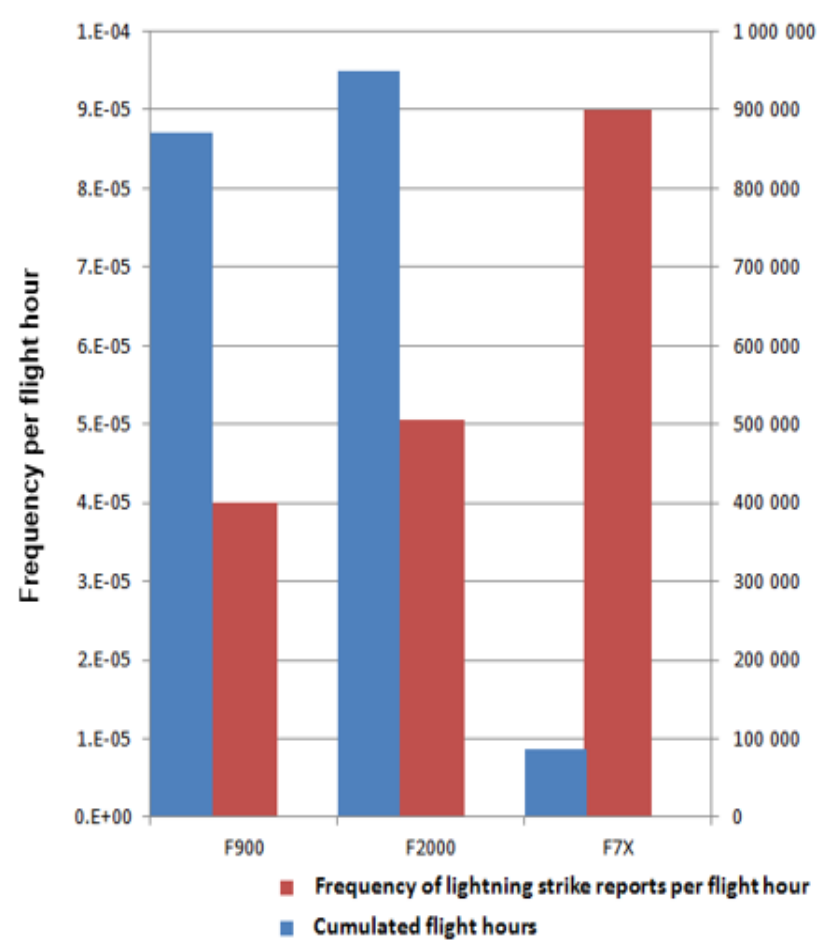

Figure 3. Lightning frequency of occurrence in function of Falcon Type

The general trend is the same for F900 and F2000 which have approximately the same frequency of lightning strike reported per flight hour, suggesting an equivalent lightning frequency of occurrence. These statistics are the most accurate since these aircrafts have cumulated significant number of flight hours.

It can be observed than F7X frequency of lightning strike reported is twice that one of F900 and F2000, suggesting an higher lightning frequency of occurrence.

F7X had not cumulated as many flight hours as other families, the probability may per consequence be distorted. As all the F7X are outfitted with winglets, another questioning arises: have the winglets an influence on lightning strike frequency of occurrence?

\section{Falcon fleet lightning events - operation base distribution}

The lightning frequency of occurrence is highly dependent on aircraft geographical areas of operation because of the unequally distribution of thunderstorms across all geographical areas on Earth.

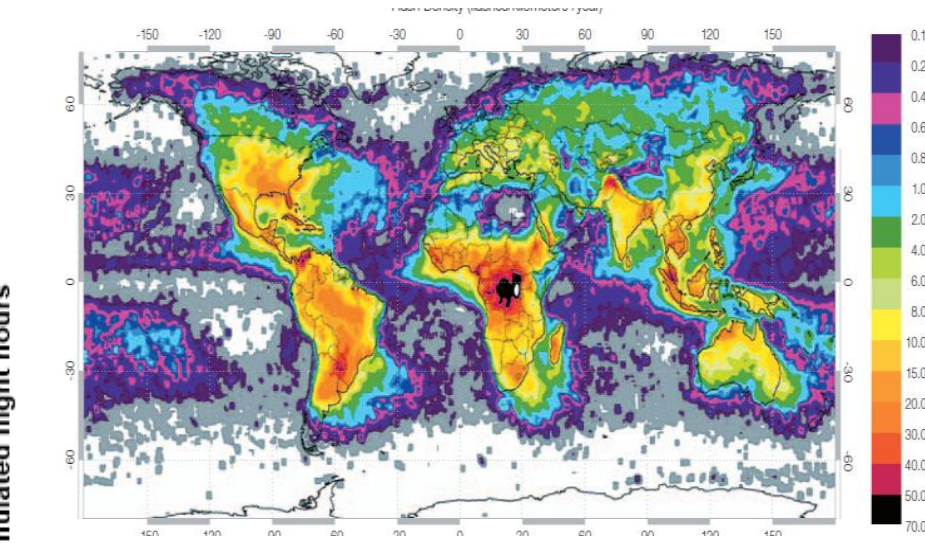

Figure 4. Worldwide distribution of lightning strike density (flashes/kilometers²/year) April 1995 - February 2003

(Source: NASA)

This map shows the distribution of lightning strike density on Earth and highlights this great geographical variation. On one hand, we have low density areas closed to 0 for oceans and polar areas and on the other hand, high density areas for hot and humid continental areas where the density can reach 70 lightning strikes per $\mathrm{km}^{2}$ in central Africa for example. It is per consequence interesting to have a better overview of the Falcon fleet operation distribution considered in this analysis.

Falcons fleet are operated all over the world, even though the lightning strike location may not directly match with operators base location, this approximation remains sensed as Falcons mostly flight in areas close to their operation bases. In the following barograph, lightning strike reported has been counted per base and divided by the cumulated flight hours for each base during the period of study.

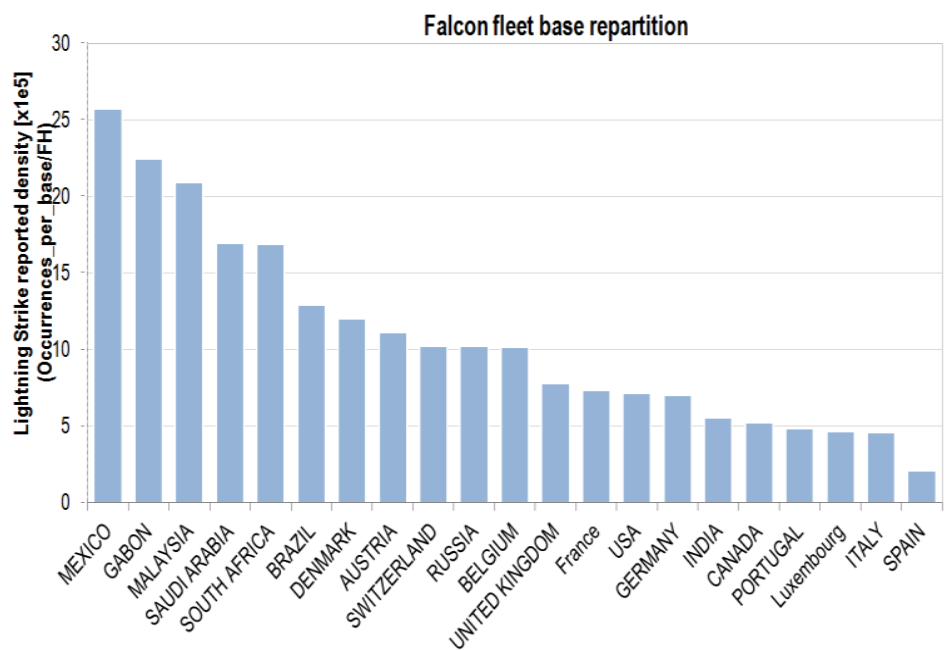

Figure 5. Lightning strike densities reported per operation base

First countries where the lightning density is the most important are in accordance with the previous worldwide lightning strike density map. Mexico, Gabon, Malaysia or Saudi Arabia are located in high lightning strike density regions concentrated around the equatorial area. 


\section{Falcon fleet lightning events - flight parameter influential factors}

The flight parameter that most increases the probability of being struck is the altitude. Current data indicated that aircrafts are frequently struck during takeoff and landing phases, at altitude comprised between 4,500 and 16,000 feet while flying through cumulonimbus where lightning activity is the most active.

These observations are now compared on the following figure with Dassault Aviation experience on its Falcons fleet.

On the 164 lightning strikes registered, 37 of them had been compiled with the flight phase information.

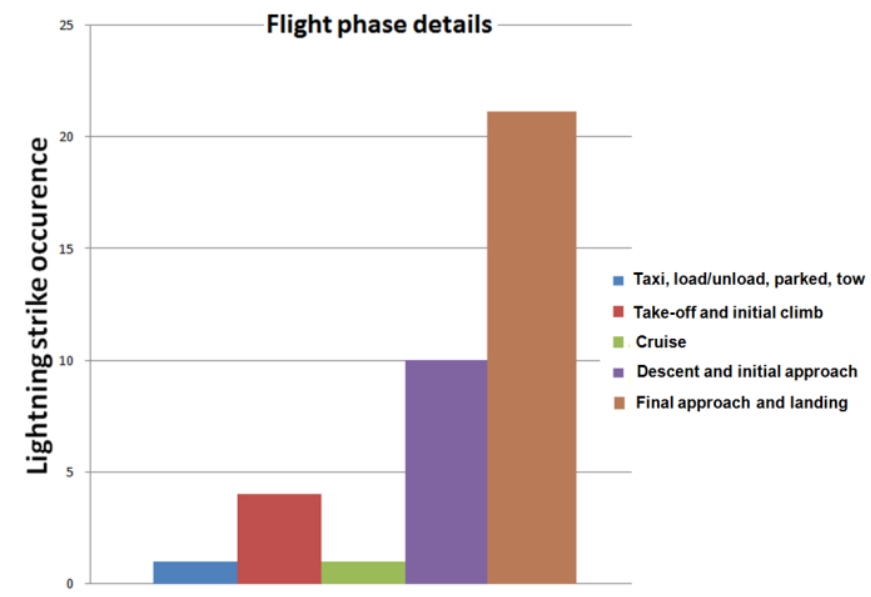

Figure 6. Falcons fleet flight phases during lightning events

These results are fully consistent with standard collected data; most of the registered lightning strikes appeared during descent/approach/landing flight phases and with a lower probability during take-offs.

The altitude was precisely mentioned for 27 of the registered strikes, the distribution is again consistent with that one observed on commercial aircrafts:

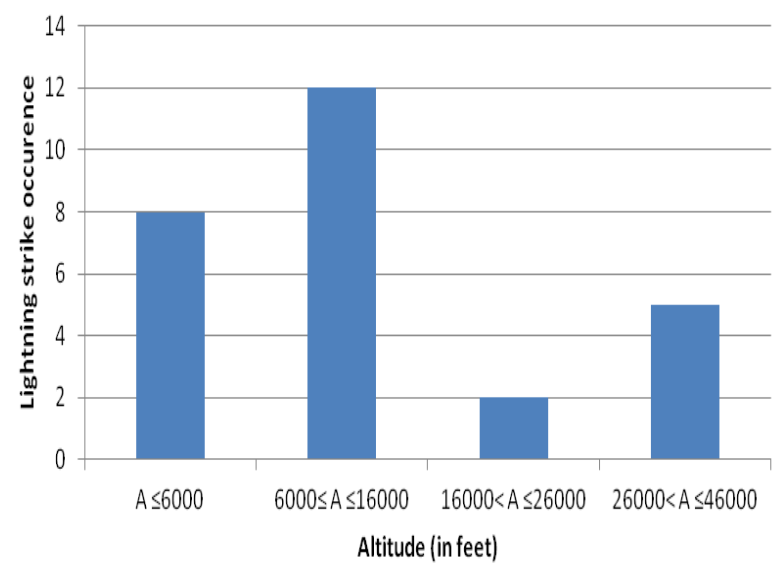

Figure 7. Aircrafts altitude during lightning events
Most of the lightning strikes occurred on Falcon fleet at altitude lower than 16,000 feet, the probability decreases significantly at higher altitude.

\section{Falcon fleet lightning events - lightning strike damages distribution}

This part is dedicated to the analysis of the lightning strike localizations observed on F900, F2000 and 7X structures.

The objective is to confront these data with normative Falcon zonings defined in accordance with ARP5414/ED-91 Aircraft Lightning zoning standard document.

Among the 164 lightning strike events reported, 150 contain enough data to determine which aircraft areas were damaged.

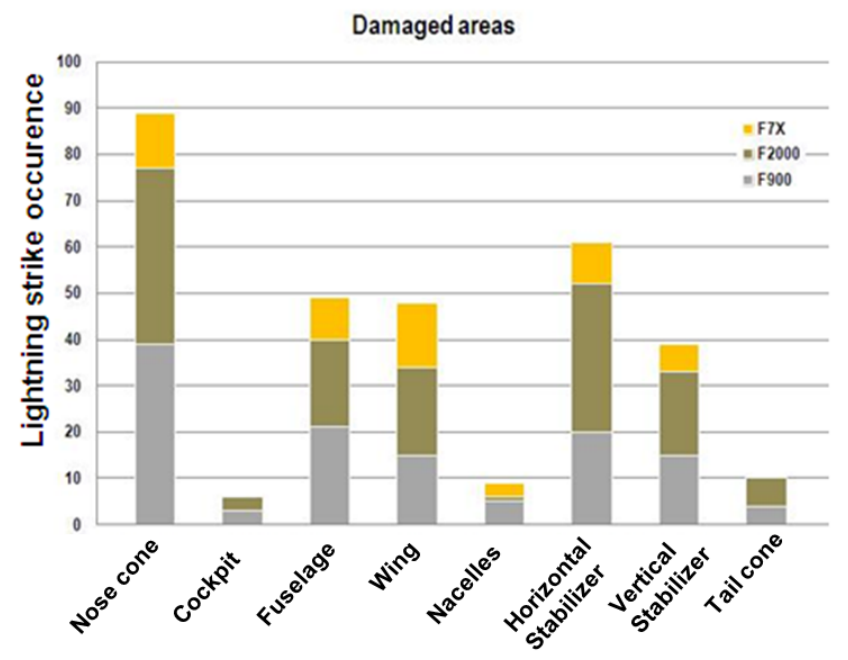

Figure 8. Lightning damages areas observed on Falcon fleet

This damages distribution demonstrates that the nose cone is the privileged initial lightning attachment zone. Its structure is identical for these 3 aircraft types and composed of two different parts:

- The dielectric radar part protected by lightning diverters

- The carbon composite avionic bay protected by bronzemesh layer

Damages on nose cone were reported 89 times on 164 events with the following damages distribution:

- Strikes only on lightning diverters: 29 cases

- Pitting only: 19 cases

- Both effects: 41 cases 


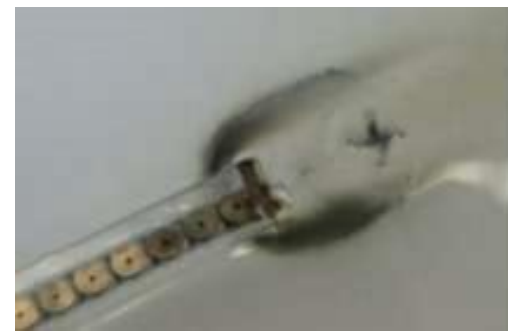

Figure 9. Typical burnt mark at lightning diverter fixing screw

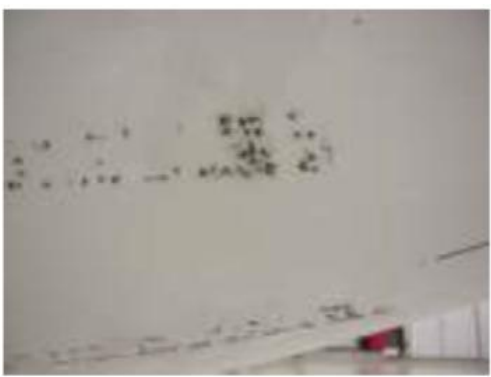

Figure 10. Typical nose cone pitting damage

Lightning diverters have then been impacted 70 times on 89 cases. This ratio confirms that there is an efficient lightning protection by facilitating the air ionization process to protect underlying weather radar. Pitting impacts are mostly located in the carbon composite avionic bay part.

Horizontal Stabilizer appeared as the privileged lightning "exit" zone, a bit more frequent than wings and vertical fin. The fuselage is also often struck by lightning because of the sweeping phenomenon due to the speed of the aircraft compared to the static lightning channel.

On the contrary, the cockpit, the nacelles and the tail cone are low probability attachment areas.

On these 164 lightning registered events, 27 reports contained sufficient information to map lightning strikes attachment points with precision:

- 7 reports on F2000

- 4 reports on F2000 EX EASy (Enhanced avionic systems and changes to pressurization and oxygen systems)

- 10 reports on F900

- 6 reports on F7X

These mappings are superimposed on Falcon family respective zoning, lightning strikes are identified by red crosses (the top/bottom distinction on the F7X zoning is not respected).

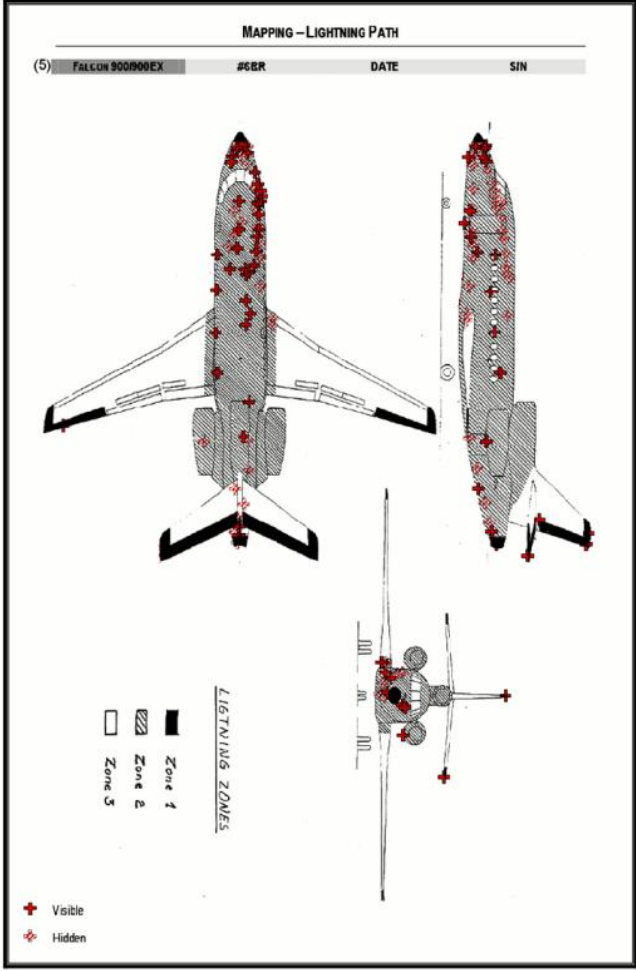

Figure 11. Falcon 900 lightning attachment locations

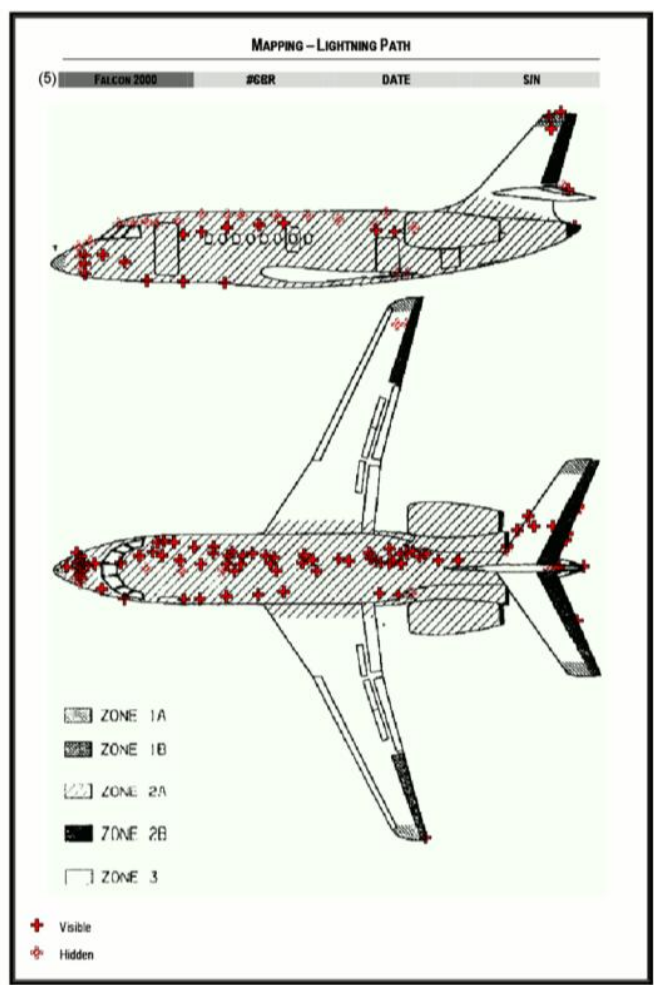

Figure 12. Falcon 2000 lightning attachment locations 


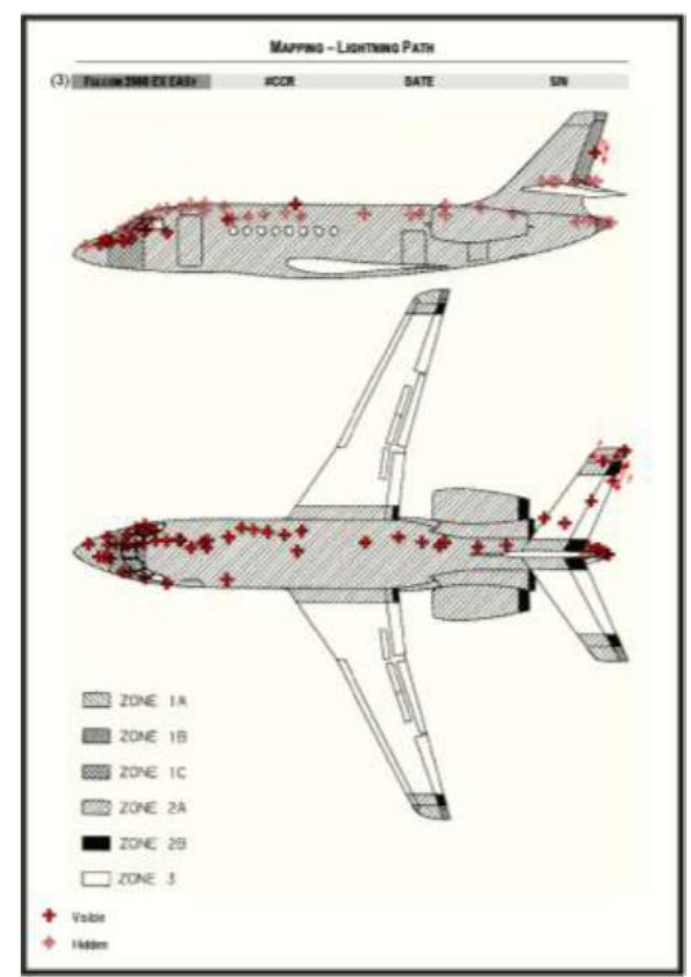

Figure 13. Falcon 2000EX Easy lightning attachment locations

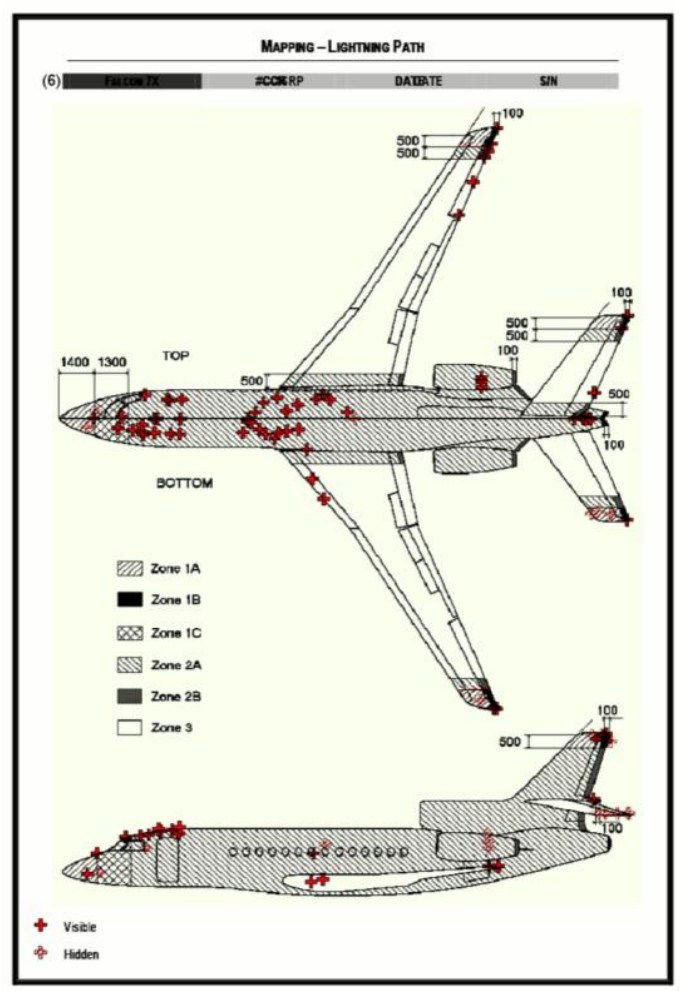

Figure 14. Falcon 7X lightning attachment locations

Almost all impacts are located on zones 1 and 2 as predicted by design. Most of sweeping paths correspond to lightning strike configurations: Nose to tail cone/horizontal stabilizer or vertical fin.
Few attachments points have been detected in conduction zone 3, characterized by its low probability of attachment. Some occurred on inboard slat, ailerons, wing box tip, horizontal stabilizer leading edge and torsion box. All the damages noticed were minors.
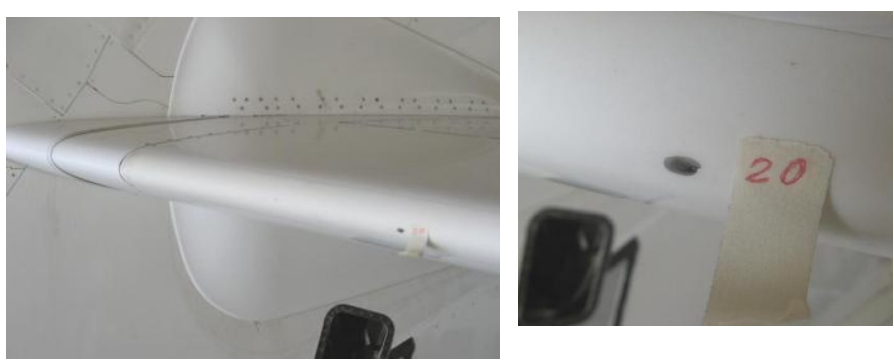

Figure 15. Lightning strike observed on a horizontal stabilizer leading edge in conduction zone 3

To mitigate these observations, it can sometimes be difficult to differentiate damages from attachment and current conduction.

It is also very interesting to observe on these mappings that no attachment have been detected in fuel tank zones, respectively:

- The root part of the wing, delimited by a $50 \mathrm{~cm}$ width band from fuselage/karman, located in swept stroke zone $2 \mathrm{~A}$

- A large section of the wing tank conduction zone 3

- Specifically for F900, a part of the rear tank located inside the fuselage in zone $2 \mathrm{~A}$ just after the trailing edge.

The sweeping process appears quiet regular on F2000 and F900. The attachment points associated with the rear part of the aircraft remain hanging on while the attachment points from the nose cone sweep along the fuselage following the stream lines of the air flow, new re-attachments occur at regular intervals all along the fuselage when the voltage drop exceeds the air breakdown voltage.

These observations do not completely match with F7X lightning strike distribution. The sweeping process is not as regular as observed on the other Falcon types. Two distinct lightning strike zones can be highlighted on the F7X fuselage. The first one, corresponding to the nose cone can be assimilated to initial attachment points. The second one, probably a re-attachment zone, is localized few meters behind on the upper fuselage part closed to the beginning of wing root.

Few re-attachment points have been detected in the rear part of the fuselage, this mapping confirms that winglets are privileged attachment points on F7X. 

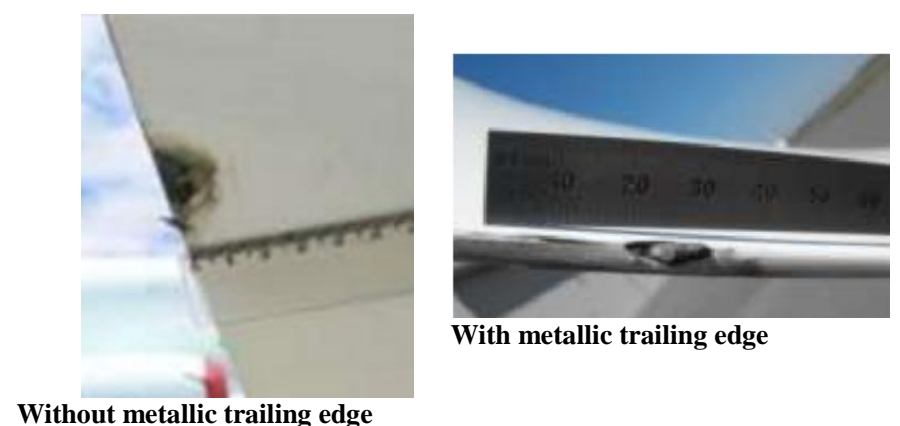

Without metallic trailing edge

Figure 16. Typical winglets trailing edge damages

32 lightning events on 164 concern aircrafts outfitted with winglets. On these 32 events, operators reported damages on winglets 16 times. Most of them have been observed on F7X winglets. Wing tips have been rarely struck on aircrafts without winglets. This observation clearly demonstrates the influence of winglets on the lightning path.

To finish, it is also interesting to note that most of the sweeping process occurred on the upper part of the fuselage, typically corresponding to approach/landing phase airflow configurations. Indeed, the more the incidence is, the more the arc root path is moved to the top of the fuselage.

\section{Initial attachment and sweeping zone computations}

The last part of this paper deals with ONERA computations which has develop a model to estimate the probability that a particular area of the aircraft to be struck by one of the lightning current components.

This model takes into account the coupling between the lightning channel, the aerodynamic flow profile and the $3 \mathrm{D}$ geometry of the aircraft.

The objective is to confront this computation with Dassault Aviation in-service experience and Falcon standard zoning to improve the lightning phenomenology understanding.

Zones with zero-risk of attachment/sweeping are represented in white while high-risk attachment/sweeping areas are in orange/red:

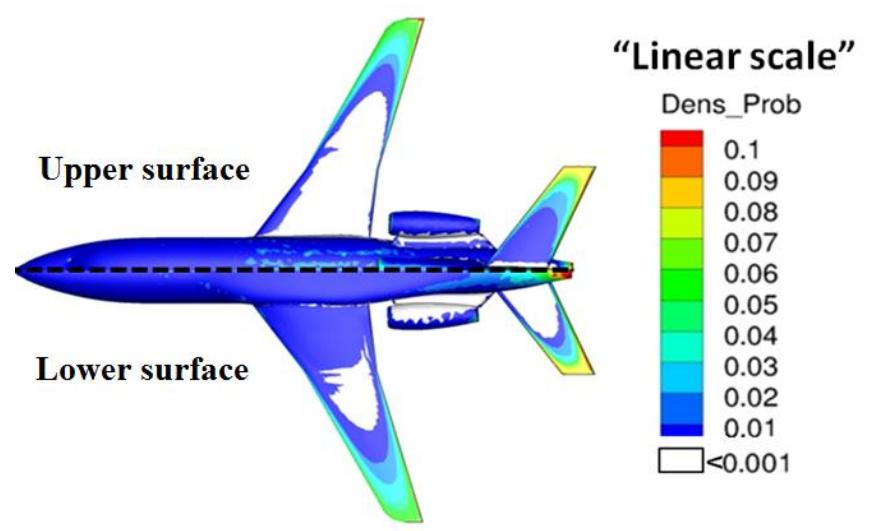

Figure 17. Falcon sweeping zone 2A computation
This computation is consistent with Dassault Aviation inservice experience. From the beginning of the wings, small areas with higher probability to encounter sweeping phenomenon can be observed on upper fuselage surface. No attachment has been reported on pylon where the computed probability is close to 0 . Lightning attachment points reported in conduction zone 3 (on inboard slat, ailerons, wing box tip, horizontal stabilizer leading edge and torsion box) are map in blue zone where the probability of attachment/sweeping is not extremely rare.

In comparison with Falcon standard zoning, the first observation which draws the attention is the dissymmetry between the upper and lower surface of the aircraft. For instance in the upper surface, most of the wing is considered in conduction zone 3 while the engine and horizontal stabilizer appeared with a higher probability to encounter sweeping phenomenon. The opposite is observed in the lower part of the aircraft. With more details, wing box root zone $2 \mathrm{~A}$ is not identified on upper surface while this one is more extended on the lower side. The same behavior is observed on horizontal stabilizer torsion box.

In tips areas, the computation seems pretty close to the normative document definition. 2 zones are highlighted, one close to the tip with a high probability of attachment and the other one next to the first one with a lower probability to be struck. These zones may be assimilated to existing tip zones $1 \mathrm{~A}$ and $2 \mathrm{~A}$, however they are more extended on the computation.

Another difference concerns the limits between the different zones which do not appeared as straight as defined in normative document.

This computation gives interesting information, additional analyses are necessary to better understand all the results. A parametric study has to be performed to evaluate the influence of all flight parameters (speed, incidence...) on the sweeping zones localization. Different aircraft shapes have to be taken into account, a specific study is also required to evaluate winglets influence on lightning path.

\section{Conclusion}

The main objective of this paper was to analyze the Falcon fleet lightning in-service experience encounter during a decade and compare this feedback with commercial aircrafts and standard zoning. A lightning event per 22,000 flight hours has been reported on Falcon fleet which suggested a low probability rate. However this is difficult to evaluate the accuracy of this statistic because all the lightning strikes may not systematically be reported by operators. Nevertheless Falcon jets flexibility, specific flight paths and their small sizes could explain a difference of lightning strike probability rate in comparison with commercial aircrafts.

As observed on commercial aircrafts, the altitude is the most influential factor on lightning events which mostly occurred 
at lower altitude during take-off, approach and landing phases.

The lightning strikes damage observations on Falcon fleet structures reveal that the nose cone and the horizontal stabilizer are the most frequent attachment points. A question arises about winglets influence on lightning frequency of occurrence because of F7X higher probability rate. Their presence clearly modifies lightning flight path, half of the F7X outfitted with winglets which encounter lightning strikes have reported damages on them.

To finish, a quantitative estimation of attachment/sweeping zones has been performed on a Falcon by ONERA. A dissymmetry between Falcon upper and lower surfaces has been introduced. However, additional studies are necessary to improve the comprehension and consolidate these results. The objective of this part is to increase the understanding of lightning interaction process with aircraft structure, without the pretension to question the validity of standard zoning which impose an efficient lightning protection design. The best example to illustrate this last point is the absence of service experience issue on Falcon fleet over the past 40 years and over a total of around 15 million flight hours. 